\title{
Prevalence of Sodalis glossinidius and different trypanosome species in Glossina palpalis palpalis caught in the Fontem sleeping sickness focus of the southern Cameroon
}

\author{
Sartrien Kanté Tagueu ${ }^{1}$, Oumarou Farikou ${ }^{2}$, Flobert Njiokou ${ }^{3}$, and Gustave Simo ${ }^{1, *}$ \\ ${ }^{1}$ Molecular Parasitology and Entomology Unit, Department of Biochemistry, Faculty of Science, University of Dschang, \\ Dschang, Cameroon \\ ${ }^{2}$ Mission Spéciale d'Éradication des Glossines, Division Régionale Tsé-Tsé Adamaoua, B.P. 263 Ngaoundéré, Cameroon \\ ${ }^{3}$ Department of Animal Biology and Physiology, Faculty of Science, University of Yaoundé I, Yaoundé, Cameroon
}

Received 24 March 2018, Accepted 21 July 2018, Published online 17 August 2018

\begin{abstract}
Tsetse flies are the cyclical vector of human and animal African trypanosomiasis. To improve vector control in order to achieve the elimination of human African trypanosomiasis (HAT) and boost the control of animal diseases, investigations have been undertaken on the tripartite association between tsetse, trypanosome, and symbionts. It is in this light that Sodalis glossinidius and different trypanosomes were identified in Glossina palpalis palpalis caught in Fontem in southern Cameroon. For this study, DNA was extracted from whole flies, and S. glossinidius and different trypanosome species were identified by polymerase chain reaction (PCR). Statistical analyses were performed to compare the trypanosome and $S$. glossinidius infection rates and to look for an association between these microorganisms. Of the 274 G. p. palpalis caught, 3.3\% (9/274) were teneral. About 35\% (96/274) of these flies harbored $S$. glossinidius. Of the 265 non-teneral flies, $37.7 \%$ were infected by trypanosomes. The infection rates of Trypanosoma congolense "forest type" and Trypanosoma vivax were $26.04 \%$ and $18.11 \%$, respectively. About $6.41 \%$ of tsetse harbored mixed infections of T. congolense and T. vivax. Of the 69 tsetse with T. congolense infections, 33.33\% (23/69) harbored $S$. glossinidius while 71.86\% (69/96) of flies harboring S. glossinidius were not infected by trypanosomes. No association was observed between $S$. glossinidius and trypanosome infections. Some wild tsetse harbor $S$. glossinidius and trypanosomes, while others have no infection or are infected by only one of these microorganisms. We conclude that the presence of $S$. glossinidius does not favor trypanosome infections in G. p. palpalis of the Fontem focus.
\end{abstract}

Key words: Glossina palpalis palpalis, Symbiont, Sodalis glossinidius, Trypanosoma sp, PCR.

Résumé - Prévalence de Sodalis glossinidius et de différentes espèces de trypanosomes chez Glossina palpalis palpalis capturé dans le foyer de la maladie du sommeil de Fontem, Sud Cameroun. La mouche tsé-tsé est le vecteur cyclique de la trypanosomiase humaine et de la plupart des trypanosomiases africaines animales. Pour améliorer la lutte antivectorielle afin d'éliminer la trypanosomiase humaine africaine et renforcer le contrôle des maladies animales, des études ont été entreprises sur l'association tripartite entre la mouche tsé-tsé, le trypanosome et les symbiotes. C'est dans cette optique que l'identification moléculaire de Sodalis glossinidius et de différentes espèces de trypanosomes a été réalisée chez Glossina palpalis palpalis capturé à Fontem dans le sud Cameroun. Pour cette étude, l'ADN a été extrait de la glossine entière et $S$. glossinidius et différentes espèces de trypanosomes ont été identifiés par PCR. Des analyses statistiques ont été réalisées pour comparer les taux d'infections des trypanosomes et de $S$. glossinidius et rechercher une association entre les deux microorganismes. Sur les 274 G. p. palpalis capturés, $3.3 \%$ (9/274) étaient des mouches ténérales. Environ $35 \%(96 / 274)$ de ces glossines abritaient $S$. glossinidius. Sur les 265 mouches non ténérales, $37.7 \%$ étaient infectées par au moins une espèce de trypanosome. Les taux d'infection de $T$. congolense "type forêt » et $T$. vivax étaient respectivement de $26.04 \%$ et $18.11 \%$. Près de $6.41 \%$ des mouches tsé-tsé présentaient une infection mixte impliquant T. congolense «type forêt» et T. vivax. Sur les 69 glossines infectées par Trypanosoma congolense, $33.33 \%$ hébergeaient $S$. glossinidius tandis que $71.86 \%(69 / 96)$ des mouches hébergeant $S$. glossinidius n'avaient aucune infection trypanosomienne. Aucune association n'a été observée entre $S$. glossinidius et les infections trypanosomiennes. Certaines mouches tsé-tsé abritent $S$. glossinidius et des trypanosomes alors que d'autres n'ont

\footnotetext{
*Corresponding author: gsimoca@yahoo.fr
}

This is an Open Access article distributed under the terms of the Creative Commons Attribution License (http://creativecommons.org/licenses/by/4.0), which permits unrestricted use, distribution, and reproduction in any medium, provided the original work is properly cited. 
aucune infection ou sont infectées par un seul de ces deux micro-organismes. Nous conclueons que dans le foyer de la maladie du sommeil de Fontem, la présence de $S$. glossinidius ne favorise pas les infections trypanosomiennes chez $G$. p. palpalis.

\section{Introduction}

Tsetse flies are the cyclical vector of most trypanosome species that cause human and animal African trypanosomiasis. Two species of Trypanosoma brucei s.l. are responsible for human African trypanosomiasis (HAT): Trypanosoma brucei gambiense causes the chronic form of HAT in Western and Central Africa, while Trypanosoma brucei rhodesiense is responsible for the acute form of HAT in East Africa. The third subspecies, Trypanosoma brucei brucei, is not implicated in human infection but causes African animal trypanosomiasis (AAT), also called nagana. In addition to Trypanosoma brucei brucei, Trypanosoma congolense, Trypanosoma vivax, Trypanosoma evansi and Trypanosoma simiae also cause AAT. In Africa, the economic losses resulting from the negative impact of AAT on African agriculture are estimated to be higher than US\$ 4.5 billion/year [1, 36]. Moreover, African farmers spend about 35 million dollars per year on trypanocidal drugs to protect and cure their cattle [5]. If African trypanosomiases were controlled, about 7 million $\mathrm{km}^{2}$ of tsetse infested area could be suitable for livestock and agriculture in Africa [30].

For HAT and AAT, very few drugs are available and resistance phenomena have been observed for some of them $[3,18]$. To prevent trypanosome infections, no vaccine is available and several approaches have been investigated in order to improve vector control. It is in this light that in depth investigations targeting bacterial flora of tsetse flies have been undertaken in the last few decades. Indeed, tsetse flies harbor three symbionts including the obligate primary symbiont (essential) Wigglesworthia glossinidia [43], the secondary (non-essential) symbiont Sodalis glossinidius [7], and the third symbiont (nonessential) known as Wolbachia [33]. The secondary and facultative symbionts $S$. glossinidius [7] are enterobacteria, which are widely spread in numerous tissues of the fly [2]. They are suited as paratransgenic organisms due to their ability to survive in the same organs with trypanosomes [6]. Sodalis glossinidius affect host longevity and may influence the host's ability to establish trypanosome infections [8]. Given their close association with their host's biology and their large tissue tropism, $S$. glossinidius could be used to produce and deliver some specific molecules (antibodies) by expressing foreign genes designed to block pathogen development [10].

In some HAT foci of southern Cameroon, the presence of $S$. glossinidius has been reported to favor trypanosome infections [12]. However, the effect of S. glossinidius on trypanosome infections could depend on the trypanosome genotype [12, 15]. Moreover, the association between $S$. glossinidius and trypanosome infections could vary according to sampling areas, since the environmental conditions could affect the life history traits of tsetse flies as well as the association with their symbiotic microorganisms.

In this study, $S$. glossinidius and different trypanosome species were identified in Glossina palpalis palpalis caught in the
Fontem sleeping sickness focus of the southern Cameroon, with the overarching goal of improving our understanding of the association between $S$. glossinidius and trypanosome infections.

\section{Methods}

\section{Ethical statement}

This study was carried out following the strict recommendations contained in the Guide for the Care and Use of Animals of the Department of Biochemistry of the University of Dschang.

\section{Study area}

The Fontem HAT focus $\left(5^{\circ} 40^{\prime} 12 \mathrm{~N}, 9^{\circ} 55^{\prime} 33 \mathrm{E}\right)$ is located in the Lebialem division of the Southwest region of Cameroon. In this forest region, the climate is of the tropical moist type with a relief made up of hills and valleys. The region is crossed by many fast-moving streams. The main activity in the Fontem HAT focus is agriculture and breeding of small livestock and poultry. In addition to wild animals, several domestic animal species including dogs, pigs, sheep, and goats are found in this focus. For this study, the entomological surveys were performed in four villages of the Fontem HAT focus including Bechati, Folepi, Besali and Menji (Figure 1).

\section{Sampling of tsetse}

Two entomological surveys were conducted in four villages (Figure 1) of the Fontem HAT focus using 30 traps in February 2015 and 12 traps in November 2016. In each of these villages, pyramidal traps [19] were set up for four consecutive days in various tsetse fly-favorable biotopes. The geographical coordinates of each trap were recorded with a global positioning system. In each village, tsetse flies were collected twice a day (from 9 to 10 am and from 3 to $4 \mathrm{pm}$ ). The collected flies were identified and numbered according to traps. Thereafter, the flies were sorted into teneral (young flies that had never taken a blood meal) and non-teneral flies. Each identified tsetse fly was subsequently put into a microtube containing ethanol at $95 \%$. The microtubes were maintained at room temperature in the field. In the laboratory, they were stored at $-20^{\circ} \mathrm{C}$ until use.

\section{DNA extraction}

DNA was extracted from whole tsetse fly using the cetyl trimethyl ammonium bromide (CTAB) method as described by Navajas et al. [29]. Briefly, the alcohol used to preserve each fly was evaporated by incubating the opened microtubes containing whole fly at $80^{\circ} \mathrm{C}$ in an oven for about 


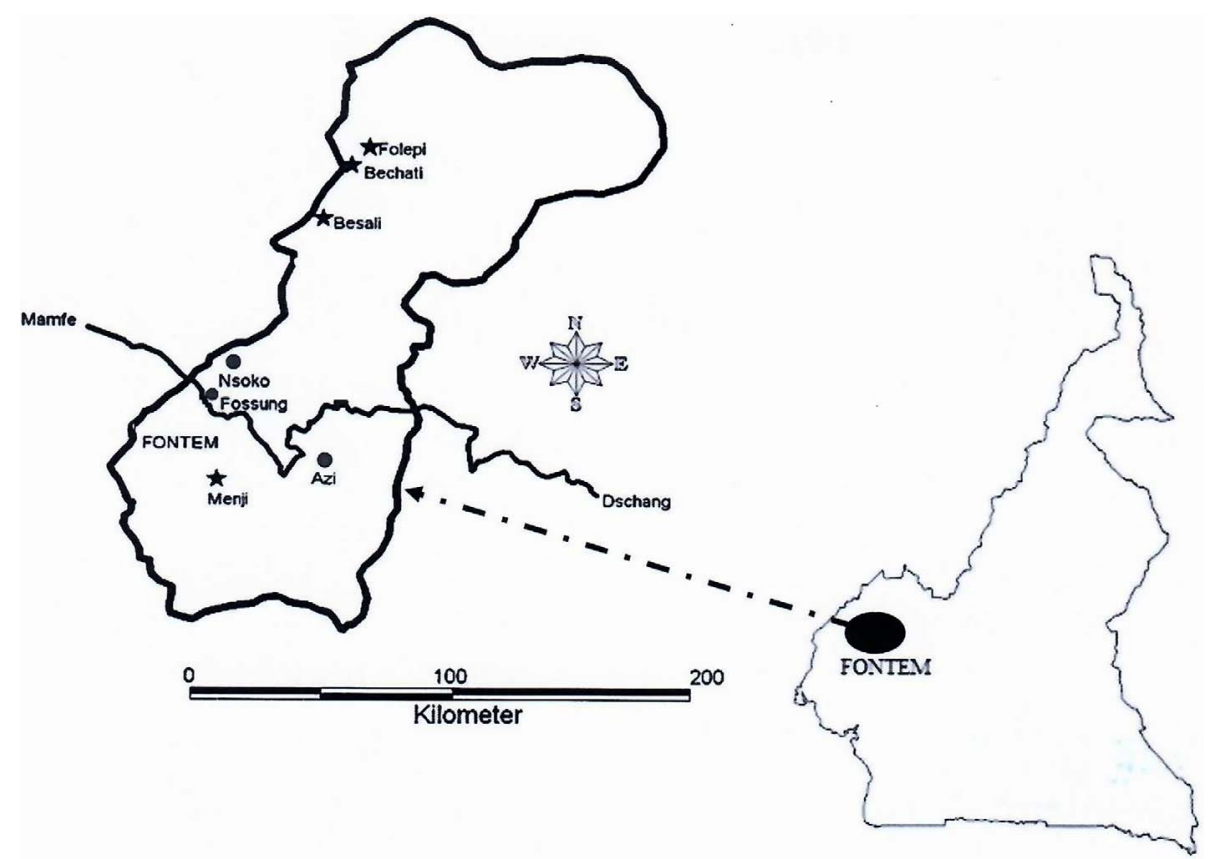

Figure 1. Map showing villages where entomological surveys where undertaken in the Fontem sleeping sickness focus. Stars: Villages where tsetse flies were trapped; circles: other villages. The road from Mamfé to Dschang is indicated in black.

$1 \mathrm{~h}$. Thereafter, each fly was disrupted with a pestle in CTAB buffer (CTAB 2\%; $1 \mathrm{M}$ Tris, $\mathrm{pH}$ 8; $0.5 \mathrm{M}$ EDTA pH 8; $5 \mathrm{M}$ $\mathrm{NaCl})$. The disrupted tissues were incubated at $60{ }^{\circ} \mathrm{C}$ for $30 \mathrm{~min}$ before the addition of chloroform/isoamylic alcohol mixture $(24 / 1 ; \mathrm{V} / \mathrm{V})$. DNA was precipitated by addition of isopropanol $(\mathrm{V} / \mathrm{V})$ and a centrifugation at $13,000 \mathrm{rpm}$ for $15 \mathrm{~min}$. The DNA pellets were washed twice with $70 \%$ cool ethanol and then dried at room temperature. DNA pellets were finally re-suspended in $50 \mu \mathrm{L}$ of sterile water before their storage at $-20{ }^{\circ} \mathrm{C}$ until use.

\section{Detection of S. glossinidius}

The presence of $S$. glossinidius was revealed by PCR with pSG2 direct (5'-TGAAGTTGGGAATGTCG-3 $\left.{ }^{\prime}\right)$ and reverse (5'-AGTTGTAGCACAGCGTGTA-3') primers as described by Darby et al. [9]. The PCR reactions were carried out in a DNA thermal cycler (Prime). Each amplification reaction was performed in a total volume of $25 \mu \mathrm{L}$ containing $20 \mathrm{pmol}$ of each primer, $2.5 \mu \mathrm{L}$ of $10 \times$ reaction buffer, $2 \mathrm{mM}$ of $\mathrm{MgCl}_{2}$, $200 \mathrm{mM}$ of each dNTPs, $4 \mu \mathrm{L}$ of DNA template, and 0.5 units of Taq DNA polymerase (New England Biolab $5 \mathrm{U} / \mu \mathrm{L}$ ). The amplification reactions involved a denaturation step at $94{ }^{\circ} \mathrm{C}$ for $5 \mathrm{~min}$ followed by 40 amplification cycles made up of a denaturation step at $94{ }^{\circ} \mathrm{C}$ for $30 \mathrm{~s}$, an annealing step at $56{ }^{\circ} \mathrm{C}$ for $30 \mathrm{~s}$, and an extension step at $72{ }^{\circ} \mathrm{C}$ for $45 \mathrm{~s}$. These amplifications were followed by a final extension step at $72{ }^{\circ} \mathrm{C}$ for $5 \mathrm{~min}$. The amplified products were resolved by electrophoresis at 100 volts for $30 \mathrm{~min}$ on $2 \%$ agarose gel containing ethidium bromide. DNA bands were visualized under ultraviolet light.

\section{Detection of trypanosomes}

Four sets of specific primers (Table 1) were used to identify Trypanosoma brucei s.l., Trypanosoma vivax, and Trypanosoma congolense "forest" and "savannah" types. This identification was done by PCR as described by Herder et al. [16]. For this identification, each PCR reaction was carried out in a final volume of $15 \mu \mathrm{L}$ containing $1.5 \mu \mathrm{L}$ of $10 \times$ PCR reaction buffer, $1.5 \mathrm{mM}$ of $\mathrm{MgCl}_{2}, 200 \mathrm{mM}$ of each dNTP, 10 picomoles of each primer (Table 1), 0.3 units of Taq DNA polymerase (New England Biolab $5 \mathrm{U} / \mu \mathrm{L}$ ) and $3 \mu \mathrm{L}$ of DNA extract. For each amplification reaction, a denaturation step at $94{ }^{\circ} \mathrm{C}$ for 5 min was followed by 40 amplification cycles. Each of these cycles included a denaturation step at $94{ }^{\circ} \mathrm{C}$ for $30 \mathrm{~s}$, an annealing step for $30 \mathrm{~s}$ at $60{ }^{\circ} \mathrm{C}$ for T. brucei s.l., T. vivax, and T. congolense "forest" and "savannah" types, and an extension step at $72{ }^{\circ} \mathrm{C}$ for $1 \mathrm{~min}$. A final extension step was performed at $72{ }^{\circ} \mathrm{C}$ for $10 \mathrm{~min}$. The amplified products were separated on $2 \%$ agarose gel containing ethidium bromide and visualized under UV illumination.

\section{Statistical analysis}

The statistical analyses were performed using StataCorp 2015 statistical software, release 14 (StataCorp LP; College Station, TX, USA). Chi-squared tests were used to compare the infection rates of $S$. glossinidius and different trypanosome species between villages. The differences were considered significant when the $p$-values were lower than 0.05 . To see whether the presence of $S$. glossinidius could favor trypanosome infections, a generalized linear model using StataCorp 2015 
Table 1. Primers used for the identification of different trypanosome species.

\begin{tabular}{|c|c|c|}
\hline Specificity & Primer sequence & References \\
\hline T. congolense "forest type" & 5'-GGACACGCCAGAAGGTACTT-3' 5'-GTTCTCGCACCAAATCCAAC-3' & Masiga et al. [24] \\
\hline $\begin{array}{l}\text { T. congolense "savannah } \\
\text { type" }\end{array}$ & $\begin{array}{l}5^{\prime} \text {-TCGAGCGAGAACGGGCACTTTGCGA-3' } 5^{\prime}- \\
\text { ATTAGGGACAAACAAATCCCGCACA-3' }\end{array}$ & Moser et al. [28] \\
\hline T. brucei s.l. & $5^{\prime}$-CGAATGAATATTAAACAATGCGCAG-3' $5^{\prime}$-AGAACCATTTATTAGCTTTGTTGC-3' & Masiga et al. [24] \\
\hline T. vivax & 5'-CTGAGTGCTCCATGTCCCAC-3' 5'-CCACCAGAACACCAACCTGA-3' & Masiga et al. [24] \\
\hline
\end{tabular}

Table 2. Results of entomological surveys and infection rates of $S$. glossinidius according to villages

\begin{tabular}{|c|c|c|c|c|c|c|c|}
\hline $\begin{array}{l}\text { Survey } \\
\text { villages }\end{array}$ & $\begin{array}{c}\text { Number of } \\
\text { traps }\end{array}$ & $\begin{array}{l}\text { Number of flies } \\
\text { captured }\end{array}$ & ADT & $\begin{array}{l}\text { Number teneral } \\
\text { flies }(\%)\end{array}$ & $\begin{array}{c}\text { Number of flies } \\
\text { analyzed }\end{array}$ & $\begin{array}{c}\text { Number of flies hosting } S \text {. } \\
\text { glossinidius (\%) }\end{array}$ & $95 \% \mathrm{CI}$ \\
\hline Bechati & 12 & 54 & 1.12 & $1(1.85)$ & 54 & $21(38.89)$ & $27.45-53.22$ \\
\hline Besali & 5 & 4 & 0.2 & $0(0.00)$ & 4 & $1(25.00)$ & $3.35-76.22$ \\
\hline Folepi & 13 & 145 & 2.79 & $7(4.83)$ & 145 & $46(31.72)$ & $23.99-39.35$ \\
\hline Menji & 12 & 71 & 1.48 & $1(1.41)$ & 71 & $28(39.44)$ & $27.96-50.4$ \\
\hline Total & 42 & 274 & 1.63 & $9(3.28)$ & 274 & $96(35.04)$ & \\
\hline$p$-value & & & & & & 0.5801 & \\
\hline
\end{tabular}

ADT: apparent density per trap per day; (\%): S. glossinidius infection rate; CI: Confidence interval.

software with $95 \%$ confidence intervals (CIs) was used. For these analyses, T. vivax was excluded because its lifecycle is exclusively completed within the mouthparts of the tsetse fly.

\section{Results \\ Entomological surveys}

During the two entomological surveys, 274 tsetse flies were collected. Details regarding results of entomological surveys are reported in Table 2. Of the 274 tsetse flies collected, 9 (3.28\%) teneral flies were identified (Table 2). No teneral flies were identified at Besali. The mean apparent fly density per trap per day (ADT) varied from 0.2 to 2.79 , with an average of 1.63. The highest ADT was recorded at Folepi.

\section{Molecular identification of S. glossinidius}

Of the 274 flies analyzed, 96 were positive for S. glossinidius, yielding an overall infection rate of $35.04 \%$. The highest infection rate of $39.44 \%$ [95\% CI $=27.96 \%-50.4 \%$ ] was observed at Menji, and the lowest rate of $25 \%$ [95\% CI $=$ $3.35 \%-76.22 \%$ ] at Besali. Despite the variations observed in the infection rates, no significant difference ( $p$-value: 0.5801 ) was observed between villages (Table 2).

\section{Molecular detection of different trypanosome species}

Of the 265 non-teneral tsetse flies analyzed, 100 (37.73\%) were infected by at least one trypanosome species. Of these 100 infected flies, $69(26.04 \%)$ were infected due to T. congolense "forest type", 48 (18.11\%) to T. vivax, and 17 (6.41\%) were mixed infections (Table 3). No infections due to T. brucei s.l. were observed. The highest infection rates of $40 \%[95 \%$ $\mathrm{CI}=29.24 \%-51.82 \%]$ for $T$. congolense and $25 \%[95 \%$ $\mathrm{CI}=3.35 \%-76.22 \%]$ for $T$. vivax were observed at Menji and Besali, respectively. The lowest infection rates of $16.98 \%$ $[95 \% \mathrm{CI}=9.08 \%-29.53 \%]$ for $T$. congolense and $15.94 \%$ $[95 \% \mathrm{CI}=10.73 \%-23.03 \%]$ for $T$. vivax were observed at Bechati and Folepi, respectively. For $T$. congolense "forest type", a significant difference was found between villages. For T. vivax, no significant difference was found between villages. Of the 100 tsetse flies with trypanosome infections, 17 (17\%) were co-infected by T. vivax and T. congolense "forest type", yielding an overall co-infection rate of $6.41 \%(17 / 265)$. Between villages, significant differences ( $p$-value: 0.0454$)$ were observed in the co-infection rates (Table 3 ).

\section{Co-infection of trypanosomes and S. glossinidius}

Of the 265 tsetse flies that were simultaneously analyzed for the presence of trypanosomes and $S$. glossinidius, 92 (34.72\%) harbored S. glossinidius and 100 (37.73\%) were infected by at least one trypanosome species. The number of tsetse flies with trypanosome infections is higher than the number of flies with $S$. glossinidius. Considering the fact that T. vivax is found exclusively in the mouthparts, the 21 tsetse flies with only $T$. vivax infections were excluded from the analyses performed here. As a consequence, only 69 flies with T. congolense "forest type" were considered during investigations on the association between $S$. glossinidius and trypanosome infections. Of the 69 flies infected by $T$. congolense "forest type", 23 (33.33\%) also harbored S. glossinidius $(\mathrm{S}+\mathrm{Tcf}+)$, while the remaining $46(66.67 \%)$ were without S. glossinidius (S-Tcf +) (Table 4). About 71.86\% (69/96) of flies harboring $S$. glossinidius were not infected by trypanosomes. The analyses performed to see if the presence of $S$. glossinidius could have an impact on the trypanosome infections $(\mathrm{Tcf}+)$ revealed no significant association $(r=-0.0831$; $p=0.7785$; $[95 \% \mathrm{CI}=-0.66-0.5])$ between these two micro-organisms (Table 4). 
Table 3. Trypanosome infections according to villages.

\begin{tabular}{lccccccccc}
\hline Villages & $\begin{array}{c}\text { No of flies } \\
\text { captured }\end{array}$ & $\begin{array}{c}\text { No of flies } \\
\text { analyzed }\end{array}$ & T+ & Tcf (\%) & 95\% CI & Tv (\%) & $95 \%$ CI & Tcf/Tv (\%) & $95 \%$ CI \\
\hline Bechati & 54 & 53 & $18^{\mathrm{a}}(33.96)$ & $9(16.98)$ & $9.08-29.53$ & $11(20.75)$ & $11.88-33.72$ & $2(3.77)$ & $0.94-13.87$ \\
Besali & 4 & 4 & $1^{\mathrm{a}}(25.00)$ & $1(25.00)$ & $3.35-76.22$ & $1(25.00)$ & $3.35-76.22$ & $1(25.00)$ & $3.35-76.22$ \\
Folepi & 145 & 138 & $48^{\mathrm{a}}(34.78)$ & $31(22.46)$ & $16.26-30.17$ & $22(15.94)$ & $10.73-23.03$ & $5(3.62)$ & $1.52-8.41$ \\
Menji & 71 & 70 & $33^{\mathrm{a}}(47.14)$ & $28(40.00)$ & $29.24-51.82$ & $14(20.00)$ & $12.22-30.99$ & $9(12.86)$ & $6.83-22.90$ \\
Total & 274 & 265 & $100^{\mathrm{a}}(37.73)$ & $69(26.04)$ & & $48(18.11)$ & & $17(6.41)$ \\
$p$-value & & & & 0.0195 & & 0.8073 & & 0.0454 \\
\hline
\end{tabular}

No: number; (\%): trypanosome infection rate; T+: tsetse flies with trypanosome infections; Tcf: Trypanosoma congolense "forest type"; Tv: Trypanosoma vivax; Tcf/Tv: co-infection of Trypanosoma congolense "forest type" and Trypanosoma vivax. CI: Confidence interval.

${ }^{a}$ some of these tsetse flies were co-infected by different trypanosome species;

Table 4. Sodalis glossinidius and T. congolense co-infections according to villages.

\begin{tabular}{lccccccc}
\hline Villages & Number of flies analyzed & S+Tcf- & S+Tcf + & S-Tcf + & S-Tcf- & Flies positive to $S$. glossinidius & Flies infected by Tcf \\
\hline Bechati & 53 & 19 & 2 & 7 & 25 & 21 & 9 \\
Besali & 4 & 0 & 1 & 0 & 3 & 4 & 1 \\
Folepi & 138 & 33 & 10 & 21 & 74 & 27 & 31 \\
Menji & 70 & 17 & 10 & 18 & 25 & 92 & 69 \\
Total & 265 & 69 & 23 & 46 & 127 & & \\
$r$ & -0.0831 & & & & & & \\
$p$-value & 0.7785 & & & & & & \\
$95 \%$ CI & {$[-0.66-0.5]$} & & & & & & \\
\hline
\end{tabular}

CI: Confidence interval; $r$ : generalize linear model coefficient; S+Tcf+: tsetse flies co-infected by S. glossinidius and Trypanosoma congolense "forest type"; S + Tcf-: tsetse flies with $S$. glossinidius and without Trypanosoma congolense "forest type" infection; S-Tcf + : tsetse flies with Trypanosoma congolense "forest type" and without S. glossinidius; S-Tcf-: tsetse flies without $S$. glossinidius and Trypanosoma congolense "forest type".

\section{Discussion}

We carried out several studies on tsetse flies to understand their biology and their bacterial flora, and also to identify the parasites infecting these flies. S. glossinidius and different trypanosome species were investigated in tsetse flies caught in the Fontem HAT focus of Cameroon, with the overarching goal of improving our knowledge on the vector competence of tsetse flies. Results of entomological surveys confirm G. p. palpalis as the only tsetse species in this focus. They are in agreement with previous observations [26, 32], highlighting the role of $G$. p. palpalis in the transmission of African trypanosomiases in the Fontem HAT focus. The apparent density of the tsetse per trap per day (ADT) of 1.63 is very low when compared to 7.9 and 4.85 obtained 20 (1998) and 10 (2007) years ago in the same area by Morlais et al. [26] and Njitchouang et al. [32]. This decrease of ADT could be linked to local disturbance resulting more likely from bush clearing and population growth which has induced climatic and environmental modifications that affected tsetse biotopes. These modifications occurred with time and subsequently, have induced some changes in the composition and host availability, the nutritional behavior of tsetse, and the transmission dynamics of trypanosomes [28, 38, 41].

The presence of $S$. glossinidius in $G$. p. palpalis caught in Cameroon confirms results obtained in two other HAT foci of the forest regions of southern Cameroon [12]. The $S$. glossinidius infection rate of $35.04 \%$ obtained here is lower than the
$64.4 \%$ and $45.3 \%$ reported in G. $p$. palpalis caught at the Bipindi and Campo HAT foci of Cameroon, which are located more $400 \mathrm{~km}$ from the Fontem HAT focus [12]. This is higher than the $9.3 \%$ reported in Liberia for the same tsetse species [24]. These differences could be linked to sampling areas since each area is characterized by specific environ mental factors that affect tsetse biology as well as the symbiotic association, and subsequently the vertical transmission of S. glossinidius from mother to offspring. When environmental factors are stable, like in insectariums, the transmission rate of symbiotic micro-organisms from mother to offspring is quite high [37]. For colonies of G. p. gambiense and G. m. morsitans from Burkina Faso that were maintained in insectariums, the infection rates of $S$. glossinidius reached $100 \%$ [14].

Comparing the $S$. glossinidius infection rates between different tsetse species [20, 24, 42], the high variation observed could be explained by the intrinsic characters of each tsetse species. For the same stimuli (internal or external), tsetse species will respond differently (differential behaviors) because of their specific biological characters that induce variations in the molecular interactions between tsetse and its symbiotic microorganisms and consequently, in the infection rates of different symbionts. The high variation reported above could also result from certain differences in analytical methods. In our study for instance, whole tsetse fly was used while in previous studies, tsetse flies were dissected and investigations were performed on isolated tissues. 
The identification of $T$. congolense and $T$. vivax confirms results obtained in the same area $[26,40]$. In the same villages, these trypanosomes have previously been detected in tsetse and different domestic animals; indicating their active transmission. Our results corroborate those reported in western, eastern and central African where the same trypanosome species were detected in different tsetse species [11-13, 23, 26, 34, 35]. They are also in agreement with results obtained in a variety of wild and domestic animals despite the fact that none of these animals were investigated in this study [17, 31, 39, 40]. This wide distribution of T. vivax and T. congolense indicates their ubiquity and the presence of appropriate vertebrate hosts. The high infection rate of $T$. congolense forest "type" is linked to the geographical localization of the Fontem HAT focus because this species is mainly found in the forest regions. It can also be explained by the fact that whole tsetse fly were analyzed, and the infection rates reported here are the combination of infections occurring in different tissues such as mouthparts and midguts.

Although single infections were predominant, about $6.41 \%$ mixed infections involving T. congolense forest and T. vivax were identified. This result corroborates data reported in tsetse [25, 31] and domestic animals [39] of Cameroon and other African countries [21, 22, 35]. It is important to point out that the identification of different trypanosome species was performed on whole tsetse fly and consequently, we do not know whether these infections were immature or mature, and which organ or tissue was infected. It is also unknown whether the mixed infections identified were from the same organ or tissue. Without such information, it becomes difficult to foresee the impact of mixed infections on the transmission and the dynamics of trypanosomes from tsetse to vertebrate hosts. Remarkably, the trypanosomes ( $T$. vivax and $T$. congolense) reported in mixed infections can be found in their metacyclic forms in the mouthparts of tsetse flies. In such conditions, these trypanosomes can be simultaneously transmitted to vertebrate hosts. The mixed infections identified in this study therefore highlight a high probability that tsetse flies harbor or transmit several trypanosome species. If such transmission occurs, it becomes important to know which parasite could develop rapidly and what could be the impact of such infections on the transmission dynamics and animal health. Investigations on mixed infections in vertebrate hosts have shown mutual suppression and their advantages for the infected host [4]. As for vertebrate hosts, understanding how mixed infections evolve in tsetse flies and their potential impacts on the transmission dynamics of trypanosomes are areas for future investigation. The high infection rate observed in this study indicates active transmission of different trypanosome species. It highlights that the animal African trypanosomiases remain a serious threat to animal health and to the rural economy in the villages of the Fontem HAT focus.

The identification of tsetse flies with co-infections of $S$. glossinidius and trypanosomes, and other with trypanosome infections and without $S$. glossinidius, or with $S$. glossinidius and no trypanosome infection, corroborates results obtained elsewhere [12]. These results show that different scenarios in the tripartite association between tsetse, trypanosomes and symbiotic microorganisms can occur in natural populations of tsetse flies. In addition to these scenarios, the teneral or non-teneral status of tsetse fly and the first blood meal taken on noninfected vertebrate host could also affect the ability of tsetse to become infected and therefore, could negate any positive influence that $S$. glossinidius might have on tsetse susceptibility.

Our results showing no significant association $(r=-0.083$; $p=0.778$ ) between the presence of $S$. glossinidius and trypanosomes infections indicate that the presence of $S$. glossinidius seems not absolutely necessary for trypanosome infections in the Fontem HAT focus. These findings are in line with those reported in other tsetse species like G. austeni [42], G. brevipalpis, G. morsitans morsitans and G. pallidipes [11] where no significant association has been reported between the presence of $S$. glossinidius and trypanosome infections. These results contrast with previous ones where the presence of $S$. glossinidius was reported to favor trypanosome infections not only in G. p. palpalis of other HAT foci of Cameroon [12], but also in other tsetse species [42]. These results highlight differences in the tripartite association between tsetse fly, S. glossinidius and trypanosomes. As a result of tsetse biology and environmental factors impacting the association between tsetse fly and its symbiotic micro-organisms, the tripartite association between tsetse, $S$. glossinidius and trypanosomes seems to vary according to tsetse species, and also to different populations (from different tsetse infested areas) of the same tsetse species. To better understand this tripartite association, more in-depth investigations on natural populations of different tsetse species in various tsetse infested areas are becoming important.

Our study on the tripartite association was based on presence/absence of trypanosome or $S$. glossinidius. Instead of focusing on this presence/absence, the genetic characterization of $S$. glossinidius strains could add additional value. In fact, Geiger et al. [15] have demonstrated that the tripartite association could be affected by specific genotypes of $S$. glossinidius and some trypanosome species, such as T. b. gambiense and T. b. brucei. Some specific S. glossinidius genotypes could affect the vectorial competence of $G$. p. gambiensis and G. m. morsitans for some trypanosome species [14]. The genetic characterization of bacteria populations could therefore enable us to improve our understanding of the tripartite association, and to better understand the real contribution of S. glossinidius to this association.

\section{Conclusion}

This study has shown that, within the same tsetse infested area, the infection rates of $S$. glossinidius and different trypanosome species do not vary significantly between villages. Our results also show that in natural conditions, some tsetse flies simultaneously harbor $S$. glossinidius and trypanosomes, while others have no infection or can be infected by only one of these microorganisms. They do not confirm previous results reporting that the presence of $S$. glossinidius seems to favor trypanosome infections in G. p. palpalis. The relationship between $S$. glossinidius and trypanosome infections seems to vary according to the tsetse infested areas. Genetic comparisons between $S$. glossinidius populations found in tsetse flies 
co-infected with both $S$. glossinidius and trypanosomes, and those found in tsetse flies without trypanosome infections, could enable us to deepen our understanding of the role of $S$. glossinidius in the vector competence of G. p. palpalis.

Acknowledgements. This study was supported by IRD through the "Jeune Équipe de Recherche Associée; JEAI EpiReTryp", the "UMR INTERTRYP" of IRD, and the University of Dschang.

\section{References}

1. Alsan M. 2015. The effect of the tsetse fly on African development. American Economic Review, 105, 382-410.

2. Attardo GM, Lohs C, Heddi A, Alam UH, Yildirim S, Aksoy S. 2008. Analysis of milk gland structure and function in Glossina morsitans: Milk protein production, symbiont populations and fecundity. Journal of Insect Physiology, 54, 1236-1242.

3. Baker N, de Koning HP, Mäser P, Horn D. 2013. Drug resistance in African trypanosomiasis: the melarsoprol and pentamidine story. Trends in Parasitology, 29, 110-118.

4. Balmer O, Stearns SC, Schotzau A, Brun R. 2009. Intraspecific competition between co-infecting parasite strains enhances host survival in African trypanosomes. Ecology, 90, e3367-e3378.

5. Budd LT. 1999. DFID-funded Tsetse and Trypanosome research and development since 1980. Economic Analysis, 2, 123.

6. Cheng Q, Aksoy S. 1999. Tissue tropism, transmission and expression of foreign genes in vivo in midgut symbionts of tsetse flies. Insect Molecular Biology, 8, 125-132.

7. Dale C, Maudlin I. 1999. Sodalis gen. nov. and Sodalis glossinidius sp. nov., a microaerophilic secondary endosymbiont of the tsetse fly Glossina morsitans morsitans. International Journal of Systematic Bacteriology, 49, 267-275.

8. Dale C, Moran N. 2006. Molecular interactions between bacterial symbionts and their hosts. Cell, 126, 453-465.

9. Darby AC, Lagnel J, Matthew CZ, Bourtzis K, Maudlin I, Welburn SC. 2005. Extrachromosomal DNA of the symbiont Sodalis glossinidius. Journal of Bacteriology, 187, 5003-5007.

10. De Vooght L, Caljon G, De Ridder K, Van Den Abbeele J. 2014. Deliver of a functional anti-trypanosome Nanobody in different tsetse fly tissues via a bacterial symbiont, Sodalis glossinidius. Microbial Cell Fact, 7(13), 156.

11. Dennis JW, Durkin SM, Horsley Downie JE, Hamill LC, Anderson NE, MacLeod ET. 2014. Sodalis glossinidius prevalence and trypanosome presence in tsetse from Luambe National Park, Zambia. Parasites and Vectors, 7, 378.

12. Farikou O, Njiokou F, Mbida Mbida JA, Njitchouang GR, Djeunga HN, Asonganyi T, Simarro P, Cuny G, Geiger A. 2010a. Tripartite interactions between tsetse flies, Sodalis glossinidius and trypanosomes - an epidemiological approach in two historical human African trypanosomiasis foci in Cameroon. Infection, Genetics and Evolution, 10, 115-121.

13. Farikou O, Njiokou F, Simo G, Asonganyi T, Cuny G, Geiger A. 2010b. Tsetse fly blood meal modification and trypanosome identification in two sleeping sickness foci in the forest of southern Cameroon. Acta Tropica, 116, 81-88.

14. Geiger A, Ravel S, Frutos R, Cuny G. 2005. Sodalis glossinidius (Enterobacteriaceae) and vectorial competence of Glossina palpalis gambiensis and Glossina morsitans morsitans for Trypanosoma congolense savannah type. Current Microbiology, 51, 35-40.

15. Geiger A, Ravel S, Mateille T, Janelle J, Patrel D, Cuny G, Frutos R. 2007. Vector competence of Glossina palpalis gambiensis for Trypanosoma brucei s.l. and genetic diversity of the symbiont Sodalis glossinidius. Molecular Biology and Evolution, 24, 102-109.

16. Herder S, Simo G, Nkinin S, Njiokou F. 2002. Identification of trypanosomes in wild animals from southern Cameroon using the polymerase chain reaction (PCR). Parasite, 9, 345-349.

17. Jamoneau V, Ravel S, Koffi M, Kaba D, Zeze DG, Ndri L, Sané B, Coulibary B, Cuny G, Solano P. 2004. Mixed infections of Trypanosomes in tsetse and pigs and thier epidemiological significance in a sleeping sickness focus in Côte d'Ivoire. Parasitology, 129, 693-702.

18. Kennedy PGE. 2004. Human African trypanosomiasis of the CNS: Current issues and challenges. Journal of Clinical Investigation, 113, 496-504.

19. Lancien J. 1981. Description du piège monoconique utilisé pour l'élimination des glossines en République Populaire du Congo. Cahiers de l'ORSTOM, Série Entomologie Médicale et Parasitologie, 19, 235-238.

20. Lindh JM, Lehane MJ. 2011. The tsetse fly Glossina fuscipes fuscipes (Diptera: Glossina) harbours a surprising diversity of bacteria other than symbionts. Antonie van Leeuwenhoek, 99, 711-720.

21. Malele I, Graske L, Knight C, Ferris V, Njiru Z, Zamilton P, Lehane M, Gibson W. 2003. The use of specific and genetic primers to identify trypanosomes infectious of wild tsetse flies in Tanzania by PCR. Infection, Genetics and Evolution, 3, 271-279.

22. Masiga DK, McNamara JJ, Laveissière C, Truc P, Gibson WC. 1996. A high prevalence of mixed trypanosome infections in tsetse flies in Sinfra, Côte d'Ivoire, detected by DNA amplification. Parasitology, 112, 75-80.

23. Masiga DK, Smyth AJ, Ayes P, Bromidge TJ, Gibson WC. 1992. Sensitive detection of trypanosomes in tsetse flies by DNA amplification. International Journal for Parasitology, 22, 909-918.

24. Maudlin I, Welburn SC, Mehlitz D. 1990. The relationship between rickettsia-like-organisms and trypanosome infections in natural populations of tsetse in Liberia. Tropical Medicine and Parasitology, 41, 265-267.

25. Morlais I, Grebaut P, Bodo JM, Djoha S, Cuny G. 1998a. Characterization of trypanosome infections by polymerase chain reaction (PCR) amplification in wild tsetse flies in Cameroon. Parasitology, 116, 547-554.

26. Morlais L, Grebaut P, Bodo JM, Djoha S, Cuny G, Herder S. 1998b. Detection and identification of trypanosomes by polymerase chain reaction in wild tsetse flies in Cameroon. Acta Tropica, 70, 109-117.

27. Moser DR, Cook GA, Ochs DE, Bailey CP, McKane MR, Donelson JE. 1989. Detection of Trypanosoma congolense and Trypanosoma brucei subspecies by DNA amplification using the polymerase chain reaction. Parasitology, 99, 57-66.

28. Mukabana WR, Takken W, Knols BG. 2002. Analysis of arthropod blood meals using molecular genetic markers. Trends in Parasitology, 18, 505-509.

29. Navajas M, Lagnel J, Gutierrez J, Bourset P. 1998. Species wide homogeneity of nuclear ribosomal ITS2 sequences in the spider mite Tetranychus urticae contrasts with extensive mitochondrial COI polymorphism. Heredity, 80, 742-752.

30. Negash M, Girma M, Seyouma E. 2007. Epizootiological importance of Glossina morsitans submorsitans (Diptera: Glossinidae) (Newstead) in the Ghibe River Valley, Southwest Ethiopia. Acta Tropica, 102, 100-105.

31. Nimpaye H, Njiokou F, Njine T, Njitchouang GR, Cuny G, Herder S, Asonganyi T, Simo G. 2011. Trypanosoma vivax, T. congolense forest type and T. simiae: prevalence in domestic animals of sleeping sickness foci of Cameroon. Parasite, 18, $171-179$. 
32. Njitchouang GR, Njiokou F, Nana Djeunga HC, Fewou Moundipa P, Asonganyi T, Cuny G, Simo G. 2011. A new Transmission Risk Index of Human African Trypanosomiasis and its application in the identification of high transmission sites of sleeping sickness in the Fontem focus of South-West Cameroon. Medical and Veterinary Entomology, 25, 289-296.

33. O'Neill SL, Gooding RH, Aksoy S. 1993. Phylogenetically distant symbiotic microorganisms reside in Glossina midgut and ovary tissues. Medical and Veterinary Entomology, 7, 377-383.

34. Onyekwelu KC, Ejezie FE, Eze AA, Ikekpeazu JE, Ezeh RC, Edeh GC. 2017. Prevalence of trypanosome infection in tsetse flies from Oji River and Emene axis of Enugu state, Nigeria: A preliminary report. Tropical Parasitology, 7, 98-102.

35. Reifenberg JM, Cuisance D, Frezil JL, Cuny G, Duvallet G. 1997. Comparison of the susceptibility of different Glossina species to simple and mixed infections with Trypanosoma (Nannomonas) congolense savannah and riverine forest types. Medical and Veterinary Entomology, 11, 246-252.

36. Reinhardt E. 2002. Travailler ensemble: la mouche tsé-tsé et la pauvreté rurale. Chronique ONU, https://www.un.org/french/ pubs/chronique/2002/numero2/ 0202p17_la_mouche_tsetse.html.

37. Rio RVM, Yi-neng W, Filardo G, Aksoy S. 2006. Dynamics of multiple symbiont density regulation during host development: tsetse fly and its microbial flora. Proceedings of the Royal Society of London Series B: Biological Sciences, 273, 805-814.
38. Rueda LM, Patel KJ, Axtell RC, Stinner RE. 1990. Temperature-dependent development and survival rates of Culex quinquefasciatus and Aedes aegypti (Diptera: Culicidae). Journal of Medical Entomology, 27, 892-898.

39. Simo G, Asonganyi T, Nkinin SW, Njiokou F, Herder S. 2006. High prevalence of Trypanosoma brucei gambiense group 1 in pigs from the Fontem sleeping sickness focus in Cameroon. Veterinary Parasitology, 139, 57-66.

40. Simo G, Njitchouang GR, Melachio TTT, Njiokou F, Cuny G, Asonganyi T. 2014. Population genetics of Trypanosoma brucei circulating in Glossina palpalis palpalis and domestic animals of the Fontem sleeping sickness focus of Cameroon. Parasites and Vectors, 7, 156.

41. Staak C, Kämpe U, Korkowski G. 1986. Species identification of blood meals from tsetse flies (Glossinidae): results 1979-1985. Tropical Medicine and Parasitology, 37, 59-60.

42. Wamwiri FN, Alam U, Thande PC, Aksoy E, Ngure RM, Aksoy S, Ouma JO, Murilla GA. 2013. Wolbachia, Sodalis and trypanosome co-infections in natural populations of Glossina austeni and Glossina pallidipes. Parasites and Vectors, 6, 232.

43. Wang J, Weiss BL, Aksoy S. 2013. Tsetse fly microbiota: form and function. Frontiers in Cellular and Infection Microbiology, 3,69 .

Cite this article as: Kanté Tagueu S, Farikou O, Njiokou F \& Simo G. 2018. Prevalence of Sodalis glossinidius and different trypanosome species in Glossina palpalis palpalis caught in the Fontem sleeping sickness focus of the southern Cameroon. Parasite 25, 44.

Reviews, articles and short notes may be submitted. Fields include, but are not limited to: general, medical and veterinary parasitology; morphology, including ultrastructure; parasite systematics, including entomology, acarology, helminthology and protistology, and molecular analyses; molecular biology and biochemistry; immunology of parasitic diseases; host-parasite relationships; ecology and life history of parasites; epidemiology; therapeutics; new diagnostic tools.

All papers in Parasite are published in English. Manuscripts should have a broad interest and must not have been published or submitted elsewhere. No limit is imposed on the length of manuscripts.

Parasite (open-access) continues Parasite (print and online editions, 1994-2012) and Annales de Parasitologie Humaine et Comparée (1923-1993) and is the official journal of the Société Française de Parasitologie. 